concept analogous to exposure, so measurements must be expressed either in terms of fundamental quantities such as fluence and energy, or else by means of an instrument whose response is modified so that under specified radiation geometries the meter reading gives an approximate estimate of the dose delivered by all neutrons irrespective of energy.

The CEGB has a range of equipment for producing electromagnetic radiation and neutrons. Electromagnetic radiation is produced by sealed radioactive sources and by X-ray sets whose beams can be filtered to give narrow spectra. Neutrons are produced by a range of sealed sources, and by the $\mathrm{D}(\mathrm{d}, \mathrm{n}) \mathrm{He}$ and $\mathrm{T}(\mathrm{d}, \mathrm{n}) \mathrm{He}$ reactions. Thermal neutrons are available by moderating the $2.5 \mathrm{MeV}$ beam produced by the first of these reactions.

Experience with the facility has shown that many instruments have undesirable features which would have been impossible to identify without comprehensive radiological investigation. Some instruments, for instance, fall back to less than full scale at very high intensities, and some neutron instruments respond to gamma radiation of high intensity or high photon energy. Manufacturers sometimes introduce design changes with serious radiological consequences, and even the best instruments seem to develop faulty characteristics during their lifetime. But, apart from the need to identify faults, the principal task of the facility is to adjust instruments so that their scales read as accurately as possible, and to ensure that the user has all the information needed to interpret the scale reading correctly.

\section{Safety Testing}

THE collapse of the North Sea drilling rig Sea Gem and the cause of the Michael Colliery fire were two of the more spectacular investigations undertaken by the Safety in Mines Research Establishment during 1967, but the work of the establishment, under the Ministry of Power, covers every safety problem in the mines, including breathing appliances, methods of detecting mine gases and both gas and dust explosions. The work of the SMRE, under H. T. Ramsey, the director, is reported in the 1967 annual report (HMSO, 8s. 6d.).

Because of the SMRE's research in metallurgy and fatigue strengths, the establishment was asked to examine tie bars from the Sea Gem after it sank, killing 13 men. The bars were found to have been flame-cut from mild steel plate, which produced brittle areas under the cut surfaces. Some of the flame grooves had been filled with weld metal which extended the brittle areas. The results presented to the public inquiry concluded that "failure of tie bars ... was the most probable prime cause of the collapse".

The fire at Michael Colliery caused the death of nine men and was one of the most serious in recent years. Although it was impossible to investigate the site, the fire is known to have spread rapidly, and the section of roadway first affected was lined with polyurethane foam to reduce the emission of fire-damp into the roadway and the leakage of air out of the roadway into the waste. Further investigations have shown that, even though the foam contains a flame-retarding agent, it is still potentially highly flammable and needs to be covered with an incombustible coating such as asbestos cement.
Other preventive work at the establishment included studies of various types of self-rescuers which are to be adopted generally by the National Coal Board. Models produced in Germany have been fitted with a heat exchanger which keeps the temperature of the inspired air within a tolerable range, a great improvement over previous devices. More work needs to be done, however, on reducing breathing resistance and allowing for the presence of dense smoke. Improvements have also been made in techniques for measuring airborne dust by light-scattering methods, and a laser system has been developed that can measure both particle concentration and size distribution in a dusty atmosphere.

\section{Green Light for Reform}

AT last the administrative structure of the National Health Service may get the shake-up which most people agree it badly needs. At least, in a Green Paper published last week, Mr Kenneth Robinson, the Minister of Health, has set out briefly but clearly some reforms (National Health Service: The Administrative Structure of the Medical and Related Services in England and Wales, HMSO, 3s. 6d.). Everybody will be interested to see how well his kites fly.

The main theme of the paper is that the functions of the present hierarchy of committees-involving executive councils, regional hospital boards and boards of governors with their hospital management committees-should be replaced by a single authority in each area and that area authorities should be responsible for some important functions which are now in the hands of the local authorities. The present tripartito system is generally criticized for failing to provide the necessary coordination between the numerous services, and few tears are likely to be shed over its disappearance.

Mr Robinson envisages the whole new set-up as consisting of some 40 to 50 area health boards, each covering a large area and "having full scope for tho efficient and imaginative development of comprehensive services". These services would include various hospital and specialist services; community and local health services; general medical and dental practice, and the ophthalmic and pharmaceutical services as well as clinical teaching, postgraduate medical education and specialized services. Public health services would also be drawn into the general scheme. Each area board would have fifteen or sixteen board members, but the actual running and organization of services would be carried out by an exccutive formed by the senior officials of the five departments constituting each area board. One particularly welcome proposal is that the present largely lay administrative staff should be replaced by people with a broad professional knowledge of medical and related services. In areas with medical schools one or two additional members might be appointed to the boards on the nomination of universities. $\mathrm{Mr}$ Robinson maintains that central Government would retain its "guiding role", but that the area boards would on the whole be allowed to manage their own affairs without interference. The function of the Minister of Health would be to lay down general principles and to secure the coordination of services administered by the separate area boards. Mr Robinson's statement that such a transfer of re- 